\title{
Modeling and Calculating of Residual Stress and Strain of Butt Welded Joint
}

Mô phỏng và tính toán ứng suất dư và biến dạng liên kết hàn giáp mối

\author{
Nguyen Tien Duong \\ Hanoi University of Science and Technology, Hanoi, Vietnam \\ *Email: duong.nguyentien@hust.edu.vn
}

\begin{abstract}
The non-uniform thermal expansion and contraction resulting from welding processes cause residual stresses and strains. Experimental studies on measuring welding residual stresses and strains of structure are costly and sometimes they are not possible. Previously, analytical methods with idealized models were developed to determine the welding residual stresses and strain. Recently, numerical methods are constructed to analyze the stresses and the strains in welded structures. This paper presents the calculation results of residual stress and welding strain in butt welded joint of S355J2G3 carbon steel of $5 \mathrm{~mm}$ thickness made by MAG welding process with a single pass. The calculation is performed by two methods: the imaginary force method and the finite element method. In the finite element method, the SYSWELD software is used to simulate and to determine residual stresses and strain of this welded joint. The results of finite element method are compared with those of imaginary force method to show the rationality and the advantages of finite element method. The study results have shown that in this welded joint, only the longitudinal and transverse stress components are important and the other stress components are negligible.
\end{abstract}

Keywords: Butt weld, finite element, imaginary force, residual stress, welding strain.

Tóm tắt

Sự giãn nở và co ngót do nhiệt không đồng đều bởi quá trình hàn gây ra ứng suất dư và biến dạng hàn. Các nghiên cứu thực nghiệm để đo ứng suất dư và biến dạng hàn của kết cấu rất tốn kém và đôi khi không thể thực hiện được. Trước kia, các phương pháp phân tích với các mô hình lý tưởng hóa đã được phát triển để xác định ứng suất dư và biến dạng hàn. Gần đây, các phương pháp số được xây dựng để phân tích ứng suất và biến dạng trong kết cấu hàn. Bài báo này giới thiệu kết quả tính toán ứng suất dư và biến dạng hàn trong mối hàn giáp mối thép cacbon S355J2G3 dày $5 \mathrm{~mm}$ được thực hiện bằng quá trình hàn MAG với một lớp hàn. Việc tính toán được thực hiện bằng hai phương pháp: phương pháp lực ảo và phương pháp phần tử hữu hạn. Trong phương pháp phần tử hữu hạn, phần mềm SYSWELD được sử dụng để mô phỏng và xác định ứng suất dư và biến dạng của liên kết hàn này. Kết quả của phương pháp phần tử hữu hạn được so sánh với kết quả của phương pháp lực ảo để chỉ ra tính hợp lý và ưu điểm của phương pháp phần tử hữu hạn. Kết quả nghiên cứu đã chỉ ra rằng trong liên kết hàn này chỉ có thành phần ứng suất dọc và ứng suất ngang là quan trọng còn các thành phần ứng suất khác không đáng kể.

Từ khóa: Hàn giáp mối, phần tử hữu hạn, lực ảo, ứng suất dư, biến dạng hàn

\section{Introduction}

The butt welded joint is used in many welded structures such as tanks, beams, ships, cars, motorcycles,... After welding due to the internal force of shrinkage, the structure is often deformed and warped. In addition, residual stress exists in the structures that reduces the working ability of the structure. Therefore, the determination of residual stress and deformation in butt welded joint plays an important role. The determination of residual stress and welding strain allows us to offer reasonable structural and technological measures to reduce residual stress and weld deformation in order to

ISSN 2734-9381

https://doi.org/10.51316/jst.154.etsd.2021.31.5.9

Received: January 26, 2021; accepted: October 26, 2021 increase accuracy in the fabrication and workability of welded structures.

The welding process is a highly coupled thermalmechanical process. Therefore, the calculation of welding residual stress and strain is a complicated process. At first, a heat transfer analysis is determined to obtain temperature-time history. Then, in the mechanical analysis, the transient temperature field is used as the initial heat input to obtain welding residual stresses and strains.

The S355J2G3 steel [1] is a low carbon, high tensile strength structural steel. This steel is widely used in many manufacturing industries such as crane, railway wagon, pipeline, building structure, oil and gas 
platform, offshore structure, shipbuilding, power plant,... By outstanding advantages of the MAG welding process such as flexibility, high degree of automation, high productivity,... this welding process is increasingly widely used in the fabrication of welded structures.

The imaginary force method (IFM) developed by Trochun [2] gives the solution to determine the residual stress and welding strain in welded joints. In this method, some imaginary force is chosen so that the final deformations are the same as the deformations created during welding. Analytical methods in general and the IMF in particular [2,3] often introduce assumptions to simplify calculations that are called the idealized model. These assumptions make the obtained results by the analytical methods quite far from reality. So, this method gives the coarse approximation. They are often used to determinate preliminarily welding residual stresses and strains.

Recently, numerical methods are often applied to analyze welded structures in which the finite element method is the most used. There are many softwares based on the finite element method (FEM) that were developed to analyze the stress, the strain in general and residual stress, welding strain in particular, such as ANSYS, ABAQUS, NASTRAN, MARC,... [4]. However, SYSWELD [5] is a specialized software to simulate the welding process that is commonly used.

The experimental research to measure the residual stress in welding requires modern equipment and high costs, so analytical solutions are still used to compare with simulation results [3].

In this study, both the imaginary force method and the finite element method are used to calculate residual stress and strain of butt welded joint of S355J2G3 carbon steel. The plate has a thickness of $5 \mathrm{~mm}$ and the edge is beveled in Y form. The weld is performed in one pass by MAG welding process. In the FEM, the SYSWELD software is applied in order to solve the thermal and mechanical problems in welding. It allows for determination of residual stress and strain of this welded joint.

\section{Calculation of Residual Stresses and Welding Strains by Imaginary Force Method}

The investigated specimen is carbon steel. Two plates have the same dimensions: the length $L$, the width $h$ and the thickness $\delta$ (Fig. 1a). The plates are beveled in Y form (Fig. 2) with: the groove angle $\varphi$, the welding gap $g$, the root face $f$.

In order to simplify calculations, the IFM assumed the following:

- The temperature depends only on the distance from the survey point to the weld seam; it does not change along the weld seam;

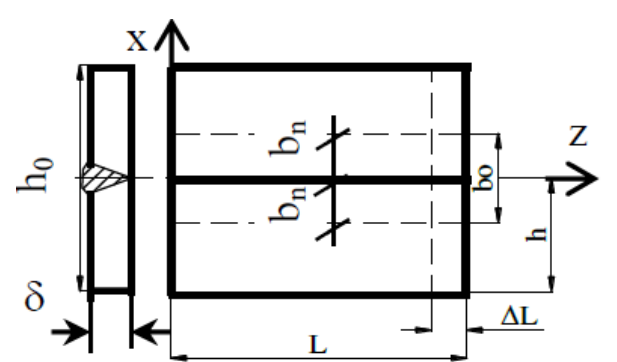

a)

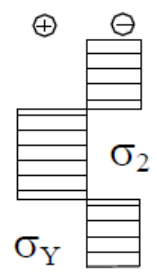

b)
Fig. 1. Dimensions of the sample (a) and distribution of longitudinal stress (b).

- The thermo-mechanical properties of materials do not depend on the temperature;

- The highest tensile longitudinal residual stress in the active stress zone is equal to the material yield stress at room temperature, $\sigma_{Y}$, while the compressive longitudinal residual stress in the reactive stress zone is constant.

Due to these assumptions the results of the IFM are idealized.

\subsection{Stress and Strain due to Longitudinal Shrinkage}

After cooling completely, the tensile longitudinal stress appears in a narrow area close to the weld which is called the active stress zone $\left(b_{n}\right)$. The value of this stress is assumed to be equal to the yield limit $\sigma_{Y}$ of the base material [2]. The compressive longitudinal stress $\left(\sigma_{2}\right)$ exists in the surrounding region which is called the reactive stress zone $\left(h_{r c}-b_{n}\right)$ (Fig. 1), where $h_{r c}$ is the real calculation width. The value of $h_{r c}$ is determined as follows:

- If $h \leq h_{c}$ then $h_{r c}=h$, here $h_{c}$ is the calculation width of the plate. The value of $h_{c}$ depends on the welding process [2]. In MAG welding process, $h_{c}$ is taken $250 \mathrm{~mm}$;

- If $h>h_{c}$ then $h_{r c}=h_{c}$.

The reactive stress $\left(\sigma_{2}\right)$ is deduced from the equilibrium of the active internal force $P$ and the reactive internal force $P^{\prime}: P=P^{\prime}$.

The active internal force $P$ is the product of stress $\sigma_{Y}$ and area $F_{0}\left(=2 . b_{n} . \delta\right)$ of this zone:

$$
P=\sigma_{Y} \cdot F_{0}
$$
force $P^{\prime}$

In the same way, it gives the reactive internal

$$
P^{\prime}=\sigma_{2} \cdot\left(F_{c}-F_{0}\right)
$$

in which $F_{c}$ is the real calculation area, $F_{c}=2 . h_{r c} . \delta$.

From (1) and (2), we can deduce:

$$
\sigma_{2}=\frac{\sigma_{Y} \cdot 2 b_{n}}{h_{r c}-2 b_{n}}
$$


According to the graphic method, the active stress zone is divided into 2 regions $\left(b_{1}\right.$ and $\left.b_{2}\right)$. The region $b_{1}$ is determined by the following formula [2]:

$$
b_{1}=\frac{0,484 \cdot q}{2 \cdot \delta \cdot v \cdot c \cdot \rho \cdot T_{\max }}
$$

where $q$ is the net heat input, in the case of arc welding, $q=U . I . \eta$ ( $I$ - welding current, $U$ - welding potential, $\eta$ - heat efficiency of welding arc); $v$ is the welding speed; $c$ is the specific heat capacity of base material; $\rho$ is the density of the base material; $T_{\max }$ is the temperature of changing from plastic state to elastic state of the base material.

The region $b_{2}$ is obtained from the formula [2]:

$$
b_{2}=k_{2 \cdot}\left(h_{r c}-b_{1}\right)
$$

where the coefficient $k_{2}$ depends on $q_{0}=\frac{q}{v \cdot \sum \delta}$ and $\sigma_{Y}$. This coefficient is determined by the graph.

The longitudinal shrinkage of the weld line is deduced from Hook's law:

$$
\Delta L=\frac{\sigma_{2}}{E} \cdot L
$$

where $E$ is the Young modulus of the base material.

The transverse stress on the weld line is calculated by the formula:

$$
\sigma_{x}=\frac{16 \cdot \sigma_{Y} \cdot b_{n} \cdot h_{r c}}{L^{2}} \cdot\left[\frac{6 z(L-z)}{L^{2}}-1\right]
$$

with $z$ is the distance from the welding start point to the considered point.

\subsection{Stress and Strain due to Transverse Shrinkage}

Total transverse shrinkage $(\Delta x)$ includes the invariable transverse shrinkage $\left(\Delta x_{0}\right)$ of base metal and the variable transverse shrinkage of each weld metal layer $(\Delta b)$ that depends on $y$-coordinate:

$$
\Delta x=\Delta x_{0}+\Delta b
$$

The invariable transverse shrinkage is determined from:

$$
\Delta x_{0}=\frac{2 \cdot \alpha \cdot q}{c . \rho \cdot v \cdot \delta}+\Delta g
$$

where $\alpha_{c}$ is the thermal expansion coefficient; $\Delta g$ is the transverse shrinkage of welding gap $(g)$ :

$$
\Delta g=\alpha \cdot T_{e} \cdot g
$$

The variable transverse shrinkage is calculated from following equation:

$$
\Delta b=2 \cdot \alpha \cdot T_{e} \cdot(y-f) \cdot \operatorname{tg} \frac{\varphi}{2}
$$

Here $T_{e}$ is the average temperature of deposit material before the transition of the highest heated points, from plastic state to elastic state.

At the top surface of the plate $(y=\delta)$, the variable transverse shrinkage is maximum:

$$
\Delta b_{\max }=2 \cdot \alpha \cdot T_{e} \cdot(\delta-f) \cdot \operatorname{tg} \frac{\varphi}{2}
$$

At the bottom surface of the plate $(y=0)$, the variable transverse shrinkage is minimum:

$$
\Delta b_{\min }=-2 . \alpha \cdot T_{e} \cdot f \cdot \operatorname{tg} \frac{\varphi}{2}
$$

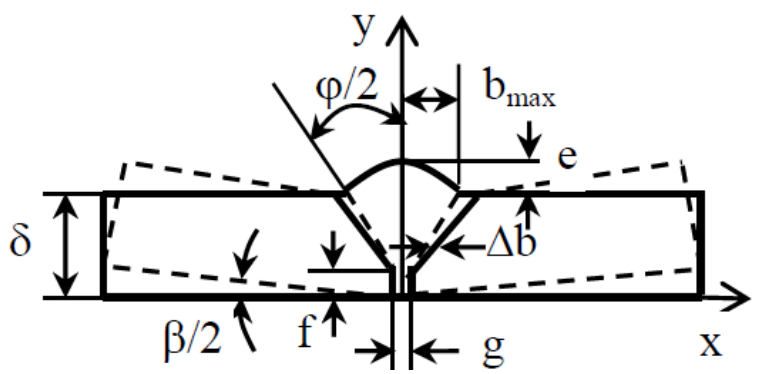

Fig. 2. Groove and angle deformation of butt weld.

The difference between the amount of variable transverse shrinkage on the top and bottom surface will cause angle deformation ( $\beta$ ) (Fig. 2):

$$
\beta=2 \cdot \alpha \cdot T_{t b} \cdot \operatorname{tg} \frac{\varphi}{2}
$$

\section{Determination of Welding Stress and Strain by Numerical Simulation Method}

In this paper, the finite element method based on SYSWELD software is used to simulate and calculate residual stress and deformation in butt weld joint by MAG welding.

In the FEM, in general, the number of elements and type of elements is fixed after meshing, but in welding, the molten metal is generated during welding then it crystallizes to form a weld. It means that, where the weld is formed, the elements were born. In order to perform the simulation and calculation only on the existing elements (not on non-existing elements), the SYSWELD simulation software has introduced the technique of "Element death and born".

A very important input parameter in the simulation of the welding process is the used heat source model. Depending on the used welding process, a suitable heat source model is selected. In arc welding, Goldak et al. [6] studied using a double ellipsoidal heat source model in which the heat source density following the Gaussian distribution is used [6-9]. This heat source model is used for arc welding in general and MAG welding in particular. In the SYSWELD simulation software, this heat source model is used to simulate the MAG welding heat source. For numerical 
simulation, author Goldak has given a shortened and equivalent form of the heat source model to provide input data for the SYSWELD software to execute [5].

In this study, the plate thickness is not high, so the width of the weld does not need to be wide, so the chosen trajectory of the torch is a straight line (without oscillation movement of welding torch). During welding, the heat source will move along the weld trajectory with a speed which is equal to the welding speed.

At the beginning of the weld line, the heat dissipation level is fast due to the low temperature of workpieces. So to ensure penetration at the beginning of the weld line, the input heat needs to be higher than the norm. In welding practice, this is done by using the "hot start" technique or a slower welding speed. At the end of the weld line, the temperature is already high so there is a risk of a burn through. Therefore, it is necessary to reduce the heat input. In practice, at the end of the weld, the input heat is reduced through the "down slope" technique or rapid movement of the torch. In the simulation, these techniques are realized through an increase/ decrease coefficient of the heat source (energy factor) in comparison with the rated heat source.

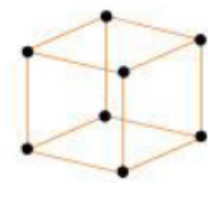

a) Brick element

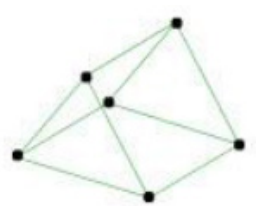

b) Triangular prism element

Fig. 3. Types of used elements.

To simulate the butt weld joint, we use 3D elements in brick-type and triangular prism elements (Fig. 3). To reduce the calculation time while ensuring accuracy, the irregular mesh is used. The weld area and its vicinity will use a fine mesh, the coarse mesh is applied for the rest.

\section{Application}

Both the imaginary force method and FEM have been carried out in butt weld joint of S355J2G3 low carbon steel plates. The chemical compositions of this material are presented in Table 1 [10]. Each plate has the dimension of $200 \mathrm{~mm} \times 75 \mathrm{~mm} \times 5 \mathrm{~mm}$. The groove is $\mathrm{Y}$ form with a beveled angle $\varphi=60^{\circ}$, the root face $f=1.5 \mathrm{~mm}$, the welding gap $g=1 \mathrm{~mm}$. The properties of base material: $\rho . c=1.15\left(\mathrm{cal} / \mathrm{cm}^{3}{ }^{\circ} \mathrm{C}\right) ; \eta=0.85$; $\alpha=12 \times 10^{-6}\left(1 /{ }^{0} \mathrm{C}\right) ; \sigma_{Y}=355(\mathrm{MPa}) ; E=2.1 .10^{5}(\mathrm{MPa})$.

The model in this study is built with 67788 nodes and 77090 elements (Fig. 4). The maximum mesh element size was $0.5 \mathrm{~mm}$ x $0.7 \mathrm{~mm} \times 1.6 \mathrm{~mm}$, while the minimum mesh element size was $3.6 \mathrm{~mm} \times 1.7 \mathrm{~mm} \times 1.6 \mathrm{~mm}$.
Table 1. Chemical compositions of S355J2G3

\begin{tabular}{|l|c|c|c|c|c|}
\hline Elements & $\mathrm{C}$ & $\mathrm{Si}$ & $\mathrm{Mn}$ & $\mathrm{P}$ & $\mathrm{S}$ \\
\hline Mass \% & 0.19 & 0.38 & 1.43 & 0.02 & 0.021 \\
\hline Elements & $\mathrm{N}$ & $\mathrm{Al}$ & $\mathrm{V}$ & $\mathrm{Nb}$ & - \\
\hline Mass \% & 0.006 & 0.05 & $<0.01$ & $<0.01$ & - \\
\hline
\end{tabular}

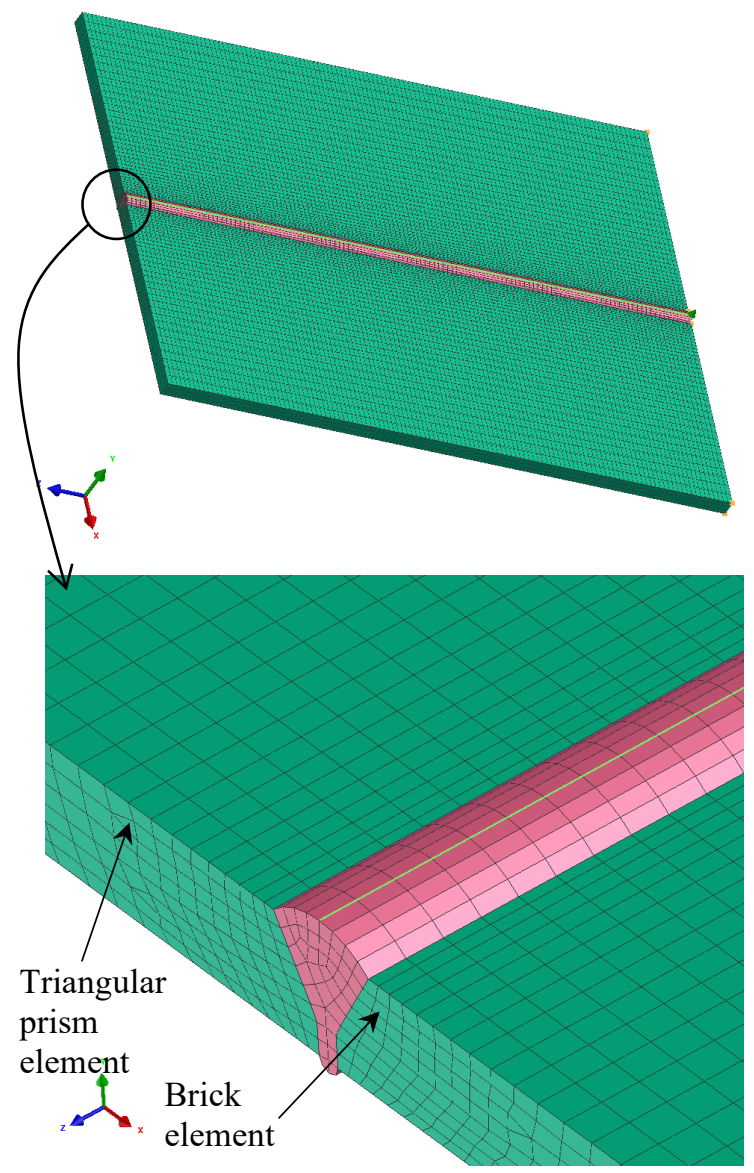

Fig. 4. Element mesh in the model.

The outer surface of the model has the convection heat exchange and the heat radiation from the model to the surrounding environment. 5950 2D surface elements are built and attached to the 3D elements on the model in Fig. 4.

In reality, the material properties depend on temperature. In the IMF method, the properties of the material are assumed that they do not depend on the temperature. The temperature dependence of physical and mechanical properties are required for the finite element method. SYSWELD software includes an extensive database about the physical and mechanical properties of S355J2G3 material at different temperatures (Fig. 5 to Fig. 9). 


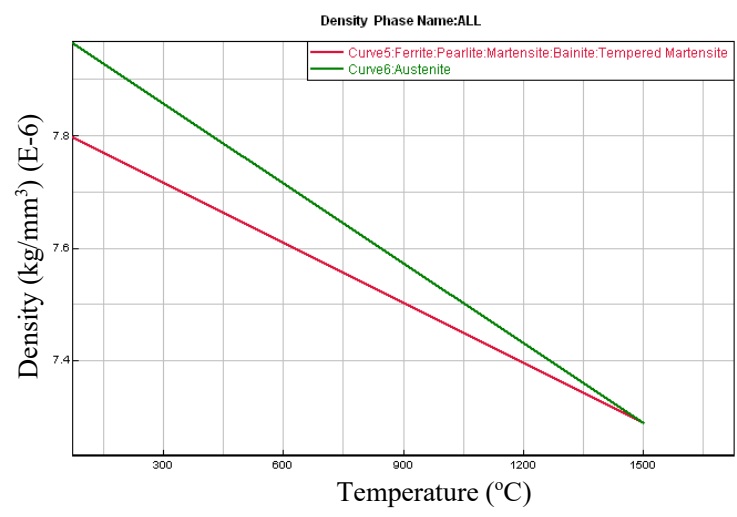

Fig. 5. Relationship between density and temperature of S355J2G3.

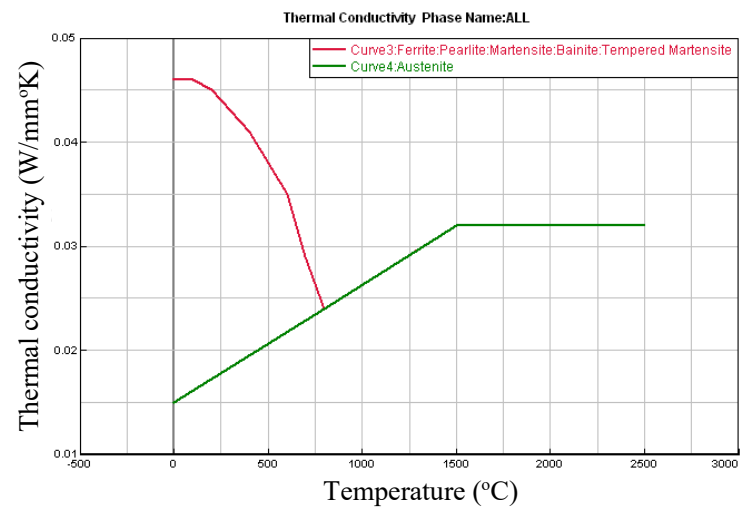

Fig. 6. Thermal conductivity of S355J2G3 depends on temperature.

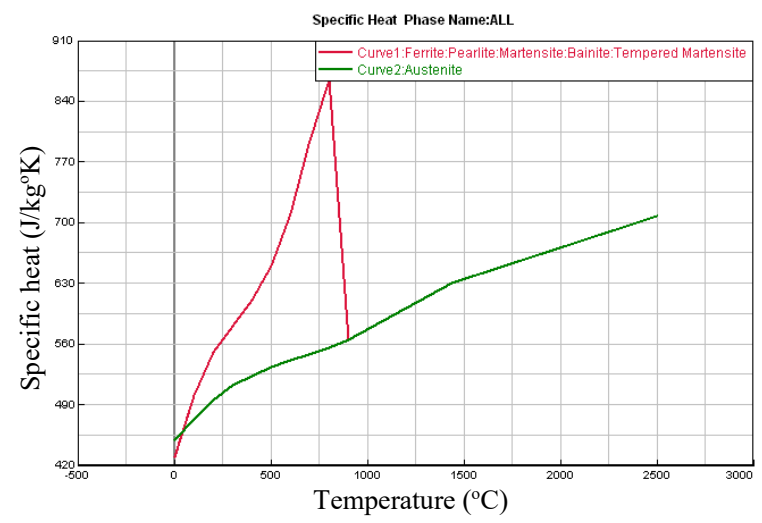

Fig. 7. Specific heat of S355J2G3 at different temperatures.

To be consistent with the calculation model in the imaginary force method, all surrounding edges of two plates are free (without clamping). However, in the simulation of the finite element method, due to the symmetry of the two plates, the displacements in $x$ and $y$ directions of all nodes on the weld bottom line are fixed. It means that the displacements in $x$ and $y$ directions of all nodes on the weld bottom line are equal to zero (Fig. 10).

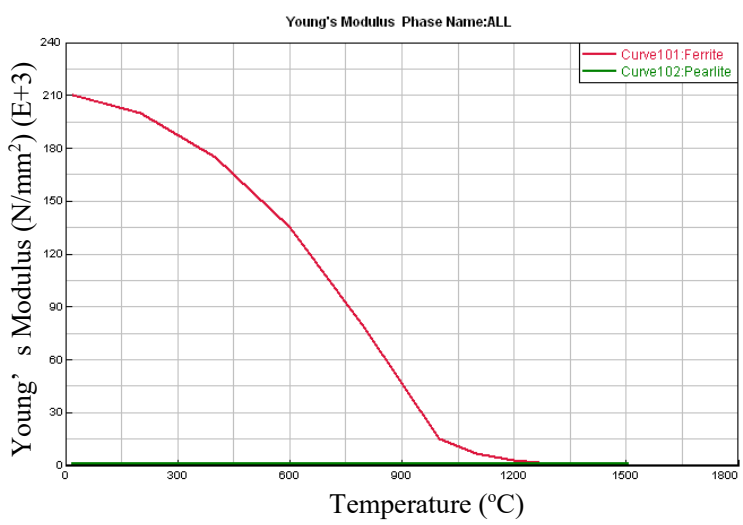

Fig. 8. Change of Young's modulus of S355J2G3.

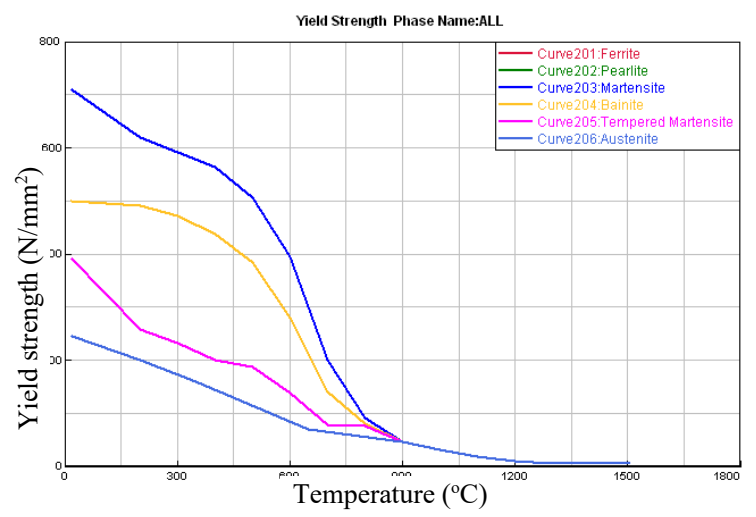

Fig. 9. Yield strength of S355J2G3

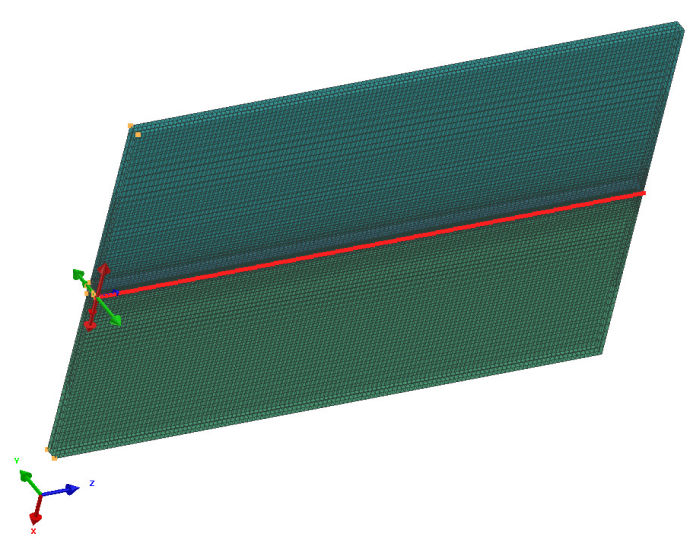

Fig. 10. Boundary condition in FEM.

\subsection{Determination of Welding Parameters}

Based on the relationship between the welding voltage and the welding current in MAG welding as well as the relationship between the welding speed and the welding current [11], the preliminary welding parameters are determined.

In order to obtain an accurate heat source model, it is necessary to check its heat source by comparing 
simulation with experiment. Firstly, the initial values of the heat source parameters of the double ellipsoid heat source model are provided, and the calculated results were compared with the actual shape of the weld pool. The continuous adjustment made the simulation results consistent with the weld pool shape, and the correct heat source model is obtained.

The final welding parameters have to ensure the requirements of shape, size, and quality, good penetration and without defects, those parameters will be got to simulate and calculate residual stresses and welding strains:

$$
I=140 \mathrm{~A} ; \quad U=21 \mathrm{~V} ; v=4,5 \mathrm{~mm} / \mathrm{s} .
$$

To ensure penetration at the beginning of the weld line, the following parameters are found: is $10 \mathrm{~mm}$;

- The length of ramp at the beginning of the weld is 1.1 .

- The energy factor at the beginning of the weld

To prevent a risk of a burn through at the end of the weld line, the following parameters are determined:

- The length of ramp at the termination of the weld is $10 \mathrm{~mm}$; is 0.8 .

- The energy factor at the termination of the weld

The plates are not preheated so the initial temperature is equal to the ambient temperature. Its value is taken as $25^{\circ} \mathrm{C}$.

The obtained weld by SYSWELD software with these welding parameters is given in Fig. 11. The fusion depth on the top surface of the weld is $0.7 \mathrm{~mm}$. It is $1.2 \mathrm{~mm}$ in the middle of the plate thickness. The fusion depth at the bottom surface of the weld is $0.3 \mathrm{~mm}$. The weld has satisfactory shape and size, sufficient penetration.

The obtained weld by experiment with these welding parameters is given in Fig. 12. The weld has a good shape, size, penetration, and without defects.

In the first step, SYSWELD software gives the temperature-time history at each node. The average thermal cycle curve at the weld toe in the center seam obtained using SYSWELD software is presented in Fig. 13. Fig. 13 shows that the highest temperature at this point is $1885{ }^{\circ} \mathrm{C}$ after welding beginning of 23.5 seconds. But just 6 seconds later, the temperature drops to $900{ }^{\circ} \mathrm{C}$. After welding beginning of 71 seconds, the temperature at this point reduces to $300{ }^{\circ} \mathrm{C}$. The cooling time from $800{ }^{\circ} \mathrm{C}$ to $500{ }^{\circ} \mathrm{C}$ of this point is 10.5 seconds. It means that the cooling rate at this point is $28.6^{\circ} \mathrm{C} / \mathrm{s}$.

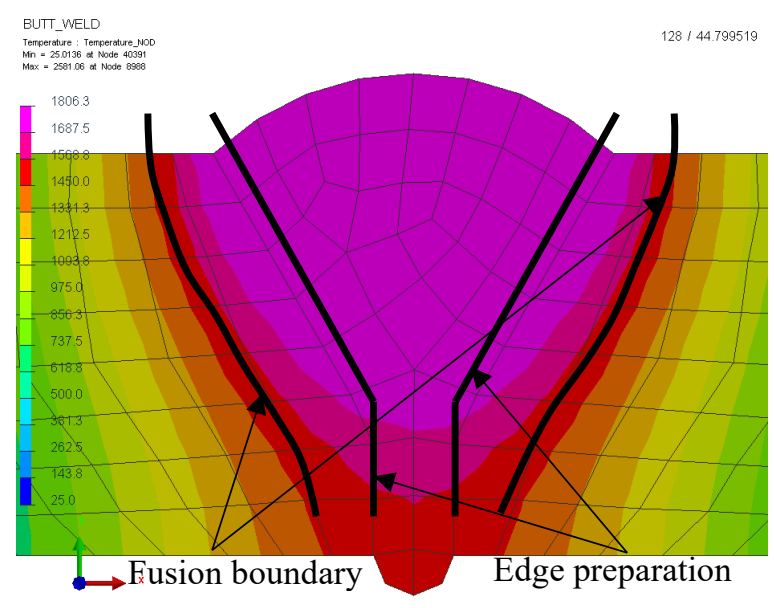

Fig. 11. Sufficient penetration weld.

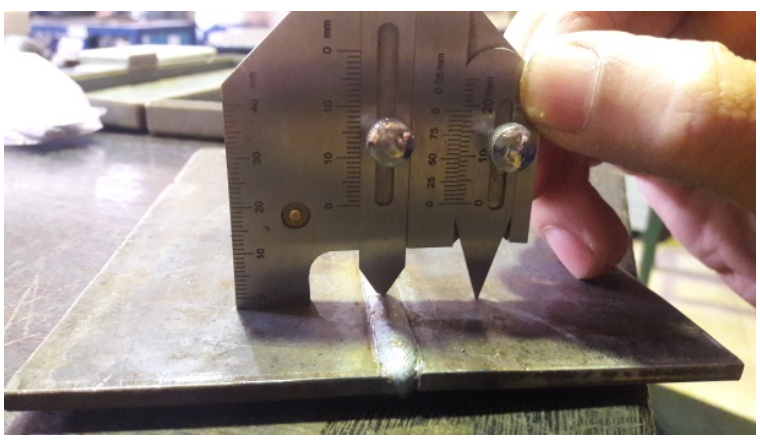

Fig. 12. Measurement of weld size.

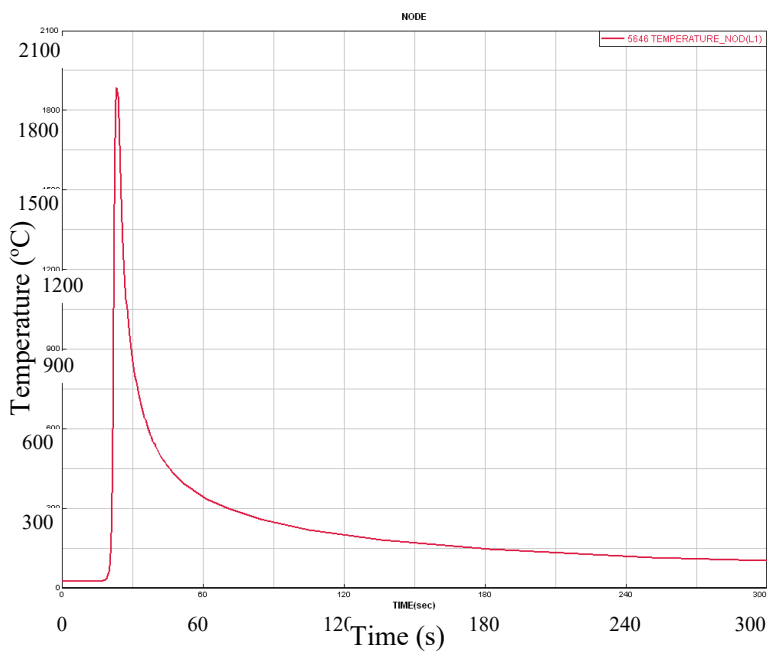

Fig. 13. Thermal cycle curve at weld toe.

In the next step, this transient temperature field is used to determine welding residual stresses and strains.

\subsection{Results Discussion}

The formulas in section 2 are used to calculate the active stress area, reactive stress area, active internal force, reaction internal force, residual stresses, and welding strains. The obtained results are presented in Table 2. The diagram of longitudinal stress due to 
longitudinal shrinkage is shown in Fig. 13. The diagram of transverse stress due to longitudinal shrinkage is given in Fig. 14.

The SYSWELD software is used to simulate the MAG welding process of this butt weld joint with the same dimensions of sample and same welding parameters which are given above. To ensure the penetration at the beginning of the weld and to avoid the risk of burn through at the end of the weld, the energy factor at the beginning of weld is found 1.1 and it is 0.8 at the termination of the weld.

The stress results showed that the stress is concentrated around and along the weld line and only stress components $\sigma_{x}$ and $\sigma_{z}$ are significant. The rest stress components $\left(\sigma_{y}, \tau_{x y}, \tau_{y z}, \tau_{x z}\right)$ are very small (Fig. 14). Therefore, only these two stress components $\left(\sigma_{x}\right.$ and $\left.\sigma_{z}\right)$ are mentioned below.

Fig. 15 gives the distribution of the longitudinal stress $\sigma_{z}$ from the weld line to the plate edge along $x$-direction (along plate width) at the bottom surface and at the plate middle of two methods (IFM and FEM). The diagram of stress $\sigma_{z}$ has the same form: this stress is tensile in the zone around the weld (active stress zone) and it is compressive in the rest zone (reactive stress zone). However, the assumption in each region of constant stress is used in IFM, so the diagram of stress $\sigma_{z}$ has a jump from the active stress zone to the reactive stress zone. The stress diagram in FEM changes steadily from positive to negative. This is more in accordance with reality.

Table 2. Results from imaginary force method (IFM) and finite element method (FEM)

\begin{tabular}{|l|c|c|c|c|}
\hline & Unit & IFM & FEM & $\begin{array}{c}\text { Error } \\
(\%)\end{array}$ \\
\hline$b_{n}$ & $\mathrm{~mm}$ & 16.7 & 22.9 & 37 \\
\hline$P$ & $\mathrm{~N}$ & 59207.8 & 81260 & 37 \\
\hline$\sigma_{l}$ & $\mathrm{MPa}$ & 355 & 478 & 34.6 \\
\hline$\sigma_{2}$ & $\mathrm{MPa}$ & -101.5 & -155.97 & 53.6 \\
\hline$\sigma_{x(x=0)}$ & $\mathrm{MPa}$ & -174.07 & -75.4 & - \\
\hline$\sigma_{x(x=l / 2)}$ & $\mathrm{MPa}$ & 87.04 & 20.9 & - \\
\hline$\sigma_{x(x=l)}$ & $\mathrm{MPa}$ & -174.07 & -78.5 & - \\
\hline$\Delta l$ & $\mathrm{~mm}$ & 0.096 & 0.09 & 6.25 \\
\hline$\Delta x$ & $\mathrm{~mm}$ & 0.285 & 0.46 & 61.4 \\
\hline$\beta$ & 0 & 0.476 & 0.365 & 23.3 \\
\hline
\end{tabular}

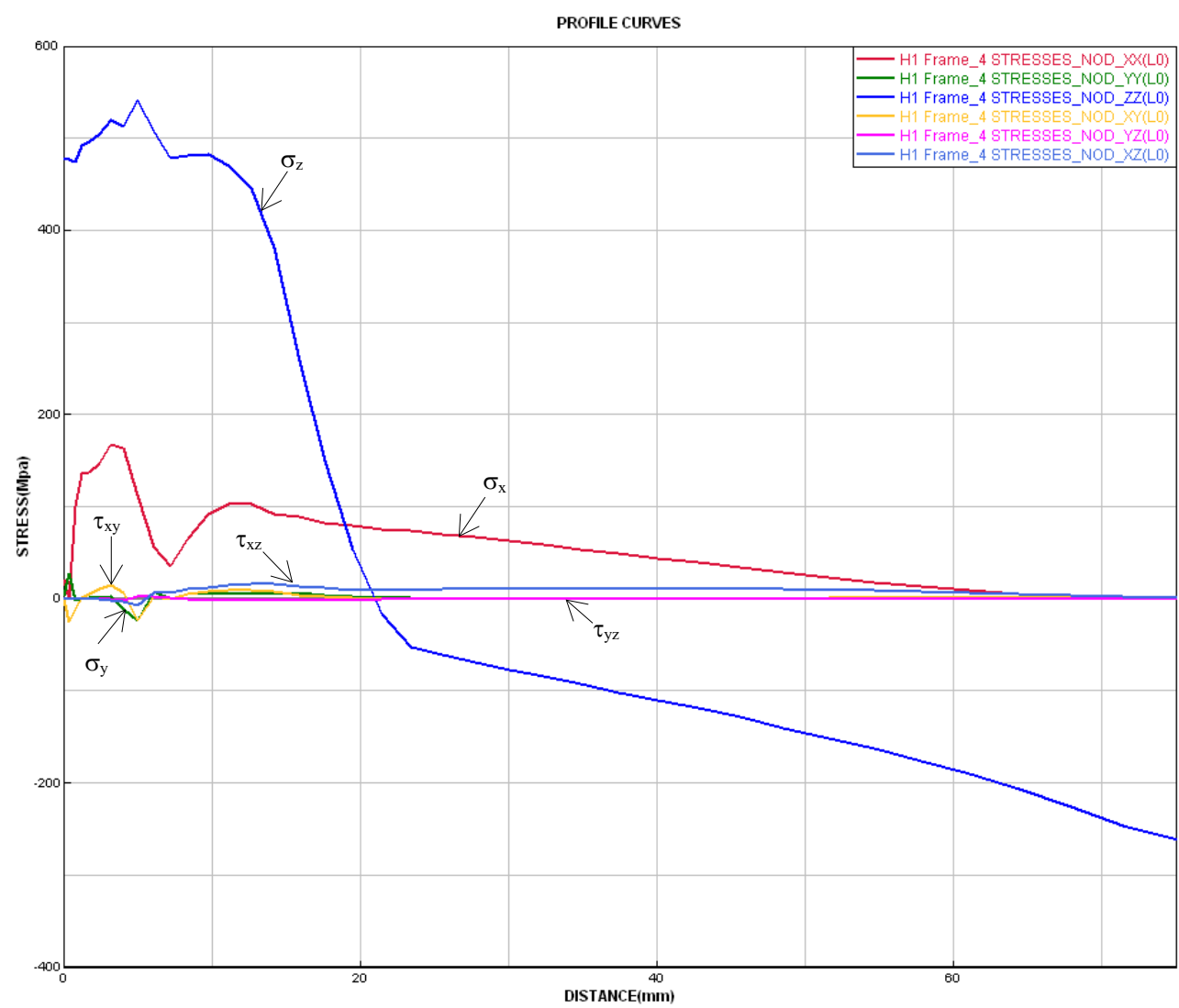

Fig. 14. Distribution of stress components in FEM from the weld line to the plate edge. 


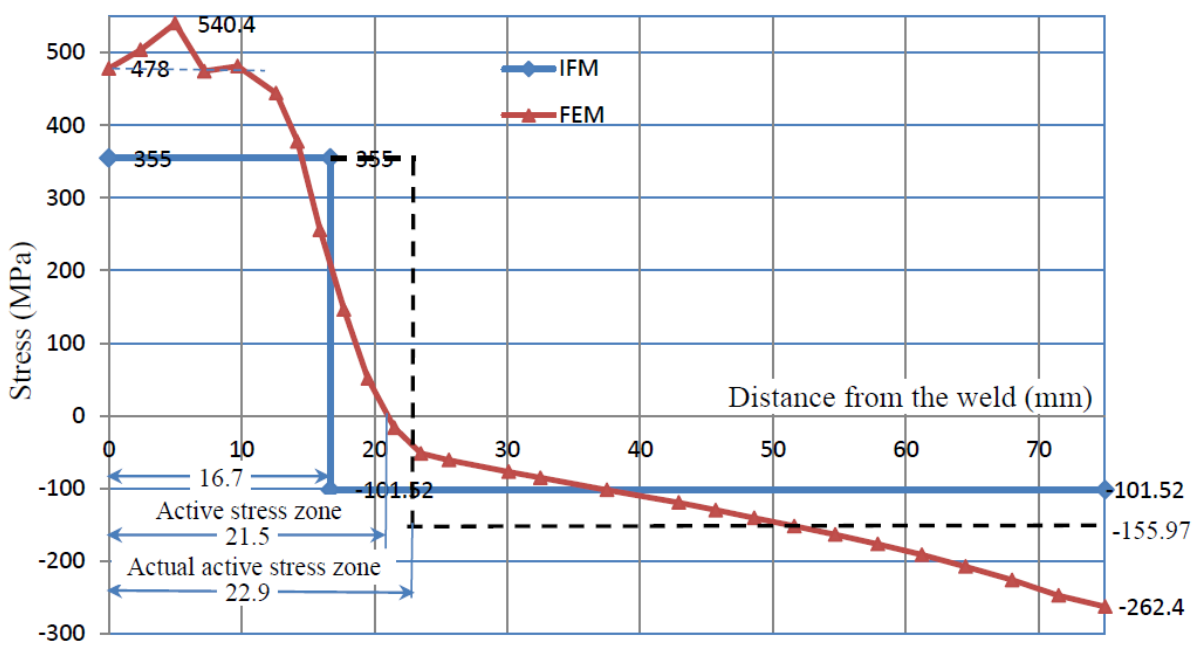

Fig. 15. Longitudinal stress distribution from the weld line to the plate edge of two methods.

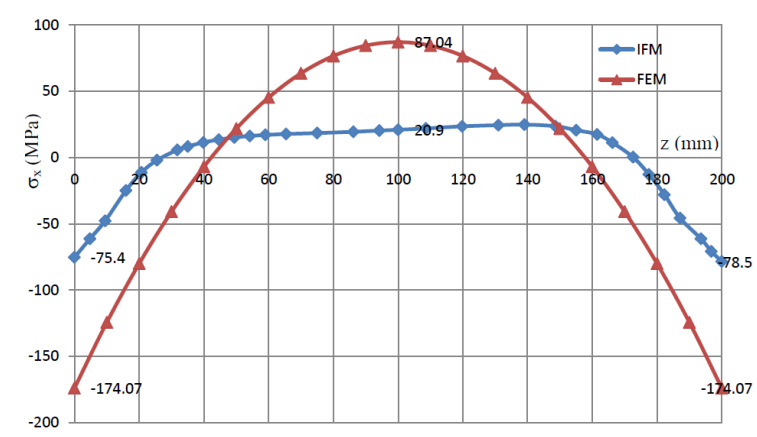

Fig. 16. Transverse stress distribution along the weld line of two methods.

The width of the active stress zone in FEM is $21.5 \mathrm{~mm}$. However, the maximum longitudinal stress $\left(\sigma_{z}=540.4 \mathrm{MPa}\right)$ in this zone exceeds the yield strength of the base material $\left(\sigma_{Y}=355 \mathrm{MPa}\right)$. Carbon steel is a material that has high ductility. So the stress only reaches the yield strength of the material. But the width of this stress zone will be enlarged to other parts of the plate until all plates reach the yield strength.

According to this principle, the width of the actual active stress zone will expand until the stress value in this zone decreases to the yield strength of the base material. The width of the actual active stress zone is determined based on the equilibrium of active internal force before and after the development yield zone.

From Fig. 15, the active internal force and the width of the new active stress zone are calculated, $P=81260 \mathrm{~N}$ and $b_{n}=22.9 \mathrm{~mm}$. The value of reactive stress varies from $0 \mathrm{MPa}$ to $-262.4 \mathrm{MPa}$. The average value of this stress is $-155.97 \mathrm{MPa}$.

The width of the active stress zone in FEM $(22.9 \mathrm{~mm})$ is larger than that in IFM method

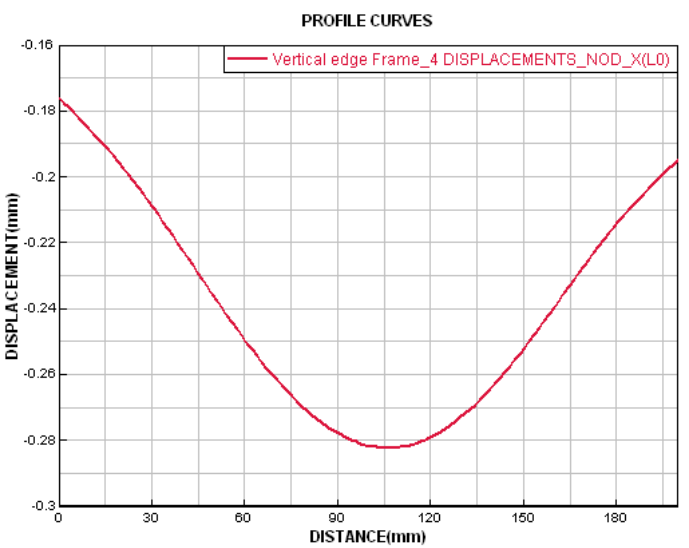

Fig. 17. The transverse shrinkage $(\Delta x)$ of half plate.

$(16.7 \mathrm{~mm})$. The value of reactive stress in FEM $(-155.97 \mathrm{MPa})$ is 1.5 times greater than that in IFM $(-101.5 \mathrm{MPa})$. So that, the reactive internal force in FEM $(81260 N)$ is higher than that in $\operatorname{IFM}(59207.8 \mathrm{~N})$.

The distribution of transverse stress $\sigma_{x}$ along the weld line in IFM and FEM is presented in Fig. 16. The values of stress $\sigma_{x}$ along the weld line in IFM and FEM at the starting $(x=0)$, at the center $(x=1 / 2)$, and the end $(x=1)$ of the weld line are given in Table 2 . There is a big difference in the transverse stress $\sigma_{x}$ along the weld line between IFM and FEM. This difference is explained as follows: the results of IFM are the value of transverse stress due to longitudinal shrinkage while the results of FEM are the total value of transverse stresses including the transverse stresses due to longitudinal shrinkage and the transverse stresses due to transverse shrinkage. In the case of welding in one direction from one end to another end of the plate, the transverse stress due to transverse shrinkage has the opposite sign of the transverse stress due to longitudinal shrinkage, so the total transverse stress in FEM will be smaller than the transverse stress due to longitudinal shrinkage in IFM. Although there is a 
difference in values between the two methods the transverse stress diagrams have the same trend: the transverse stress is compressive at both ends of the weld and it is tensile in the middle of the weld line.

The other results in the FEM are shown in Table 2. The longitudinal shrinkage of the weld $(\Delta l)$ and the angle deformation $(\beta)$ in the FEM is in good agreement with those in IFM.

The transverse shrinkage $(\Delta x)$ of the plate edge parallel to the weld line in FEM is shown in Fig. 17. This is the transverse shrinkage of half plate. The transverse shrinkage of the plate is double this amount. The transverse shrinkage of the plate is not uniform. In the middle of the plate, there is very large shrinkage while the ends of the plate have less transverse shrinkage. The average value of this transverse shrinkage of half-plate is $0.23 \mathrm{~mm}$. The total transverse shrinkage $(\Delta x)$ in FEM $(0.46 \mathrm{~mm})$ is much greater than that in IFM $(0.285 \mathrm{~mm})$.

\section{Conclusion}

The calculation results of residual stress and welding strain in butt weld from the two methods (IFM and FEM) used in this paper have shown that:

Only the longitudinal and transverse stress components $\left(\sigma_{\mathrm{x}}\right.$ and $\left.\sigma_{\mathrm{z}}\right)$ are large and the other stress components are very small, which can be ignored.

The active stress zone is under tensile stress and the reactive stress zone is under compressive stress. The results of the FEM method have shown that the stress is not evenly distributed in each of these zones.

The results of the FEM method show that the residual stress in the weld region and the vicinity of weld region is very high, even it exceeds the yield strength of the material. Especially, when the joint is subjected to a clamping, this residual stress will increase greatly. Therefore, it is necessary to determine the optimal welding parameters as well as to have reasonable technological and structural measures to reduce residual stress after welding. These problems will be done in further studies.

The active stress is always equal to the yield limit of the base material. If this stress value exceeds the yield limit, the redistribution of stress will occur. The active stress zone will be expanded.

The transverse stress at the ends of the weld is the compressive stress and in the middle of the weld, it is subjected to tensile stress.

Although the calculated stress values for each method are different, the stress distribution diagrams of the two methods have the same form.

In general, the residual stress in the FEM is always greater than that in the IFM, and the welding strain in the FEM is always less than that in the IFM.
This can be explained that the weight of the plate is not taken into account in the IFM. On other hand, S355J2G3 steel has a strong phase transformation during welding. Then the residual stress and deformation after welding of S355J2G3 steel will be the simultaneous effects of both thermal stress and stress due to phase transformation. The obtained results in the finite element method of SYSWELD software take into account both the simultaneous effects of thermal stress and phase transformation stress, while the imaginary force method takes into account only thermal stress. This is also the reason why the results of the FEM method are always much different from the IFM method.

The imaginary force method gives the coarse approximation results but it meets the needs of industries because of fast calculation and of low cost. Especially, this method is only suitable for simple welded structures. In addition, to apply this method, we need to introduce some assumptions, from which the calculation results may differ from reality. In order to calculate residual stress and deformation in complex welded structures as well as to ensure the calculation results are close to reality, it is necessary to use the finite element method.

\section{References}

[1] European Committee for Standardization, Hot Rolled Products of Structural Steels - Part 2: Technical Delivery Conditions for Non-alloy Structural Steels, EN10025-2, 2019.

[2] I.P. Trochun, Internal forces and deformations during welding, State Scientific and Technical Publishing House of Machine-Building Literature, Moscow, 1964 (Original text in Russian).

[3] M. Perić, Z. Tonković, K.S. Maksimivić, D. Stamenković, Numerical analysis of residual stresses in a t-joint fillet weld using a submodeling technique, FME Transactions, Vol. 47, 2019, pp. 183-189. https://doi.org/10.5937/fmet1901183P

[4] M. Jeyakumar, T. Christopher, R. Narayanan, B. Nageswara Rao, Residual Stress Evaluation in ButtWelded Steel Plates, Indian Journal of Engineering \& Materials Sciences, Vol. 18, December 2011, pp. 425434, 2011.

[5] ESI Group, Sysweld 2017 - Reference Manual: Description of the mathematical model, data input and computation procedures, January 2017.

[6] J. Goldak, A. Chakravarti, M. Bibby, A new finite element model for welding heat sources, Metall. Trans. B, 15B, pp. 299-305, 1984. https://doi.org/10.1007/BF02667333

[7] Dieter Radaj, Heat effects of welding - temperature field, residual stress, distortion, Springer-Verlag Berlin Heidelberg, 1992. https://doi.org/10.1007/978-3-642-48640-1_3

[8] X. Yang, G. Yan, Y. Xiu, Z. Yang, G. Wang, W. Liu, S. Li, W. Jiang, Welding temperature distribution and 
residual stresses in thick welded plates of sa738gr.b through experimental measurements and finite element analysis, Materials 2019, 12, 2426, pp. 1-15, 2019. https://doi.org/10.3390/ma12152436

[9] Nguyen The Ninh, Welding heat transfer analysis and applications, Bach Khoa Publishing House, Hanoi, 2008 (Original text in Vietnamese).
[10] GSI SLV Duisburg, The Welding Engineer's Current Knowledge: International Welding Engineering, 2010.

[11] Ngo Le Thong, Fusion electric welding technology Volume 1: Theoretical Foundations, Science and Technics Publishing House, 2007 (Original text in Vietnamese). 